\title{
USER INTERFACE FOR MOBILE APPLICATIONS: A SYSTEMATIC REVIEW OF DESIGN GUIDELINES BASED ON USER EXPERIENCE
}

\author{
Daiana Biduski, $M S c$ \\ Ericles Andrei Bellei, $M S c$ \\ João Pedro Mazuco Rodriguez, Bach \\ Ana Carolina Bertoletti De Marchi, PhD \\ Institute of Exact Sciences and Geosciences \\ University of Passo Fundo, Passo Fundo - Rio Grande do Sul - Brazil \\ e-mail: $\{130011,168729,147187$, carolina $\}$ upf.br
}

\begin{abstract}
User Experience, Guidelines, Mobile Applications
A more pleasant and intuitive user experience (UX) can be achieved with design guidelines. In this context, we systematically reviewed the literature to identify which guidelines for the design of a mobile application interface consider UX. The search was performed in the ACM, IEEE, Science Direct, Springer, and Web of Science databases. Altogether, 2007 studies were found, of which 7 met the eligibility criteria.
\end{abstract}

\section{Introduction and Background}

The increasing use of mobile devices in daily life influences directly in the mobile app (application) global market. According to a 2017 report, GSMA Intelligence (2017) estimated at 5 billion the number of mobile users around the world. The year 2016 ended with 149.3 billion downloads of apps, a record that is expected to be surpassed in 2017, predicting 197 billion downloads (APP ANNIE, 2017). New demands and opportunities are emerging, providing the steady expansion of the app development industry and the increasing number of users.

In the mobile app design process, along with the technical issues such as limitations and specifications of each device, the target audience to which the app is directed must also be considered (NIELSEN; BUDIU, 2013; ROGERS; SHARP; PREECE, 2013). Studying the users, their interaction with a product, and its respective GUI goes beyond the visual appearance of the elements that compose it. When designing for the user, certain information arranged in a GUI can condition their behavior during the interaction, modifying the navigation flow and the actions that users take to complete certain tasks (PANG et al., 2016). Design decisions should consider the user's desires, needs, and interaction goals. These requirements can provide criteria to establish an appropriate excitement capable of building a bridge between user and technology, strengthening the relationship (GRILO, 2015). Therefore, getting ahold of this information is fundamental to the acceptance and usage of an application. In this process, style guides with user-centered guidelines can be used to assist in graphical interface design projects (AHN; KIM; LEE, 2016).

Design guidelines are a set of concepts and rules used to create the interface of a system, acting as a source of reference and guidance to designers and developers (GALITZ, 2007). A set of guidelines can provide a systematic way to promote consistency and to document many user-centered design practices (LOWDERMILK, 2013).

The design of a product, along with other techniques, should provide a good user experience (UX), so the user can feel captivated and interested in repeating the interaction (FEDELE et al., 2016), coming back to the app. The user experience is inherently dynamic, due to the user's emotional state, which can be modified by different circumstances during and after the interaction with a product (VERMEEREN et al., 2010; TRIBERTI; GAGGIOLI; RIVA, 2016). Consequently, enhancing user experience is a key factor for any application's success.

User experience also involves all aspects of the end user's interaction with a company, its services, and products. Nielsen e Norman (2017) claim true 


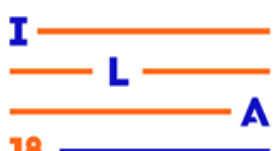

experience goes further than giving customers what they say they want. To achieve a high-quality UX, there must be a continuous merging of services from various disciplines, including engineering, marketing, graphic and industrial design, along with GUI design. According to the authors, it is essential to distinguish the concepts of UX and usability. By definition, usability is a quality attribute of the interface, revealing if a system is intuitive, easy to learn, and efficient to use, while the definition of UX fits into an even broader concept since it also covers other factors (WEEVERS, 2011).

Hassenzahl and Tractinsky (2006) affirm that UX is a consequence of an individual's internal state, including his or her predispositions, expectations, needs, and mood. These factors are also related to the characteristics of the designed system and the context in which the interaction occurs.

UX can be considered of subjective nature, since it deals with the perceptions and the thought of each person (SAURO; LEWIS, 2012). It is important to note that UX cannot be defined merely from a single concept, but instead, it is associated with subjective attributes, which are bound to the individuality and peculiarities of each user or stakeholder profile (RIVERO; CONTE, 2017; ROGERS; SHARP; PREECE, 2013).

Among the restrictions contained in the mobile applications market, is the fact that designers should always try to create a pleasant look to provide a rewarding UX (ZHANG; ALI BABAR, 2013). A positive impression of an interface is the first step towards building a meaningful relationship with the user, which seeks trust and integrity in each interaction (ROGERS; SHARP; PREECE, 2013; KUJALA; VÄÄNÄNEN-VAINIO-MATTILA, 2009). The process of elaborating or remodeling an interface is not just about inserting, changing or removing elements, such as texts, buttons, icons, and images. Decisions taken at different times and levels of a project can impact the result and should be conducted with orientation, in order to not harm the GUI's integrity, and consequently, the experience (LOWDERMILK, 2013). Rivero and Conte (2017) suggest that research could be oriented towards evaluating artifacts from early stages, such as the requirement specifications or ideas of an application. Thus, guidelines can conduct the design and the development process towards a more flexible and transparent interface design, intended to provide a more adequate and intuitive UX (AHN;
KIM; LEE, 2016).

Guidelines based on UX can explain the best practices of UI components and the understanding of their behavior. Also, these guidelines can be customized to fit each product's requirements, which makes it convenient to update guidelines based on new standards and trends (MINHAS, 2018)

With this background, the purpose of this study was to systematically review the literature to identify which guidelines for the mobile app interface design consider UX in the development process.

\section{Materials and Methods}

This study is a systematic literature review, defined as an approach to locate, evaluate, and interpret available research concerning a particular research question or phenomenon, allowing an overview of a certain subject investigation (ZHANG; ALI BABAR, 2013). For search, review, data extraction, and reporting, we followed the guidelines proposed by Kitchenham and Charters (2007).

\subsection{Research Questions}

To delineate the study, we elaborated two research questions: (1) Which guidelines for the mobile application interface design consider the User Experience? (2) How is the User Experience evaluated in the app for the formulation of a guideline?

\subsection{Search Strategy, Databases, and Criteria}

The search strategy was elaborated with keywords appropriate to the context. Search terms were grouped according to the PICO strategy (SANTOS; PIMENTA; NOBRE, 2007), as follows:

(Guideline OR Guide OR Heuristic) AND (UX OR "User Experience") AND ("Mobile application" OR "Mobile app OR "App mobile") AND (Interface $O R$ "User interface" OR UI).

The expression remained the same for all databases, considering the specifications of each search engine. We performed the search in the following databases: Association for Computing Machinery (ACM), Institute of Electrical and Electronics Engineers (IEEE), Science Direct, Springer, and Web of Science; considering keywords, title, abstract, and 
full text of the studies. Studies published until 2017 were admitted. The year 2000 was defined as the initial publication period, since it is considered the beginning of the smartphones era, in which different models of different brands were launched, standing out for its various features (RASMUSSON et al., 2004) and reaching a high number of sales (ANDERSON, 2005).

We considered studies published in related scientific journals and conference proceedings. We disregarded review articles, letters, forewords, editorials, thesis, and comments papers. Eligibility criteria (EC) for the inclusion of studies in the final analysis are:

- EC1. Studies where UX is involved in the interface design process.

- EC2. Studies that discuss some guideline, heuristic or how to use UX in the interface design.

- EC3. Studies that consider applications for mobile devices.

- EC4. Studies focused on the application interface design. Review articles, letters or short reports, editorials, thesis, comments or discussion papers were excluded.

\subsection{Study Selection Process}

Stage 1: The search string was executed in each selected database, according to each search engine specifications.

Stage 2: Studies found were preliminarily assessed, having their title, summary, and keywords examined to verify if they met the eligibility criteria. The studies that did not meet the criteria were deleted.

Stage 3: Following the eligibility criteria, the studies selected in Phase 2 were thoroughly examined with a full reading of the text, to ensure each study contained the necessary information to answer all the research questions, resulting in the definitely selected studies.

\section{Results and Discussion}

This section presents the numbers obtained in each stage of the study selection process, information, and aspects related to the included studies.

\subsection{Selection Process}

A total of 2007 studies were found with the search strategy employed. The ACM database returned 414 studies; IEEE returned 57 studies; Science Direct returned 1.168; Springer returned 345 studies; Web of Science returned 23 studies. From the total amount, 110 were excluded because they were duplicated. In Stage 2, were selected 53 studies from ACM database, 7 from IEEE, 112 from Science Direct, 95 from Springer, 9 from Web of Science, totaling 276 studies able to complete reading and start of Stage 3. In the final stage, 268 studies were removed because they were out of the scope of this research or in non-compliance with one or more eligibility criteria. At the end of Stage 3 , seven studies that met all the proposed eligibility criteria were included in the systematic review (Figure 1).

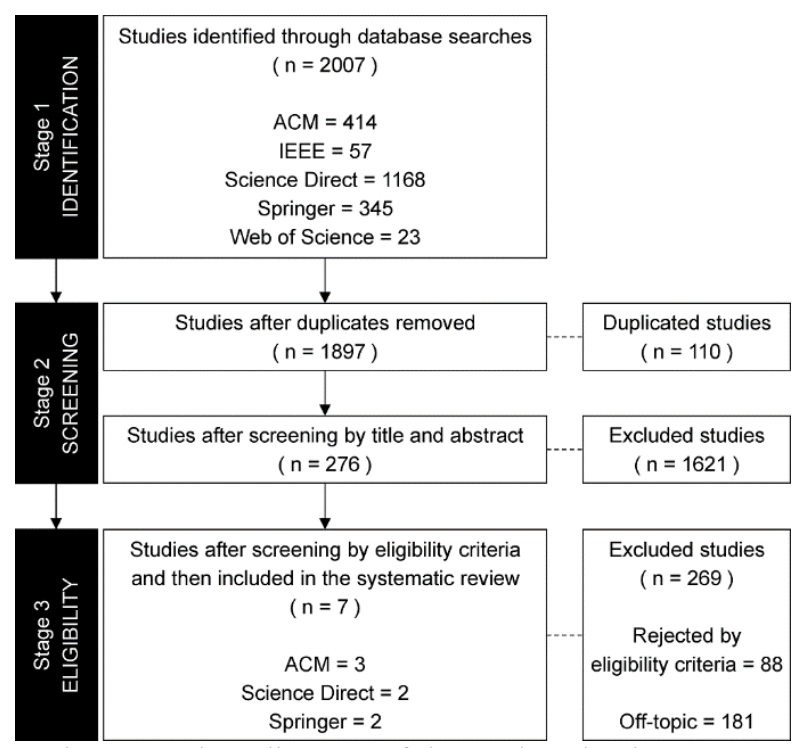

Figure 1. Flow diagram of the study selection process.

Concerning the publication year, there were studies published in 2007, 2010, and 2015. Most studies included in the systematic review were published in 2016. Although most publications are relatively recent, 2016 presented the largest number of publications, highlighting the growing concern and interest in the area, mainly in the scope of UX.

\subsection{Studies Discussion}

Interpreting the included studies, we analyze the answers to the research questions. The aim is to get an overview of the guidelines used in the applications, how they were substantiated and evaluated, and how they affected user experience. 
The study of Doherty, Coyle, and Matthews (2010) is not targeted to a specific application, but rather it is a general survey of design guidelines drawn from the literature and from a series of current projects undergoing a clinical evaluation to support mental health interventions. The authors comment that in the process of designing an application it is profitable to establish goals and identify the outcome that a system wishes to accomplish. In the mental health care area, besides goals such as usability and user experience, the connection between these elements and the impact of a new system and an intervention on the expected therapeutic results must be acknowledged.

In the study of Ribeiro et al. (2016), the inverse process is performed, where a survey with users explores their views and experiences, gathering information to verify what are their expectations and features regarding a cancer prevention application that seeks behavior change. The obtained results are transformed into guidelines used for the elaboration of $m$-Health apps. The application developed in the study is available for free download in both Android and iOS app store (RIBEIRO; ALMEIDA;

SANTOS-SILVA, 2017), where it is possible to observe how the guidelines were incorporated into the app's interface design.

The study of Irshad and Rambli (2016) contains guidelines for extending UX in mobile augmented reality (MAR) applications. The authors evaluated the experience of people towards MAR technology, conducting their survey with advertising applications. After interacting with MAR applications, participants were asked to fill in a questionnaire. The results captured through the survey were then analyzed and presented as guidelines. The authors concluded that MAR applications should promote natural and high fidelity user interfaces, maintain the functional integrity of the design. Besides designing for an engaging, productive and enjoyable experience, persuasiveness is especially important in the advertising scenario, since UX should be designed in a way that it provides complete information regarding the product and vendors.

Yang et al. (2016) reviewed the interfaces of popular apps and extracted six design patterns where UI adaptation improved navigation. Later, the authors designed a set of wireframes to illustrate how UX designers could annotate their interaction flows to communicate planned adaptation and the information needed to make the desired inferences. The authors investigated the generation of adaptive UIs with the use of machine learning, promoting the idea of building this adaption into the early stages of the design process.

Harpur and De Villiers (2015) synthesized a set of guidelines for the design and development of mobile learning environments to support successful experiences in m-learning environments. Their research is the result of a secondary study where a learning environment for higher education, called Mobile Learning Research (m-LR) was developed and evaluated. An initial set of guidelines was drawn from extensive literature research, later used in the development of $m-L R$. Then, four versions of $\mathrm{m}$-LR were examined. The assessments provided primary data used to create a new set of guidelines from real-world practice.

\subsection{Research Question 1: Which guidelines for the mobile application interface design consider the User Experience?}

The most cited guidelines in the included studies approach issues related to content, context, ease of use and user-centered design, highlighting the essential elements that an application should have to achieve satisfactory levels of UX. Table 1 presents the list of the main guidelines found in one or more studies of this systematic review. The guidelines were assembled by similar aspects to facilitate the comprehension of the results, related to the characteristics listed by Hassenzahl and Tractinsky (2006). These aspects cover the guidelines found in the studies, representing how a UX feature can reflect on each user. According to the studies, some of the included guidelines were extracted from the literature, elaborated in previous studies, while others were formulated with evaluations, assessments, and tests with users.

Liddle (2016) examines interface animation guidelines from Microsoft, Apple, and Google. The study compares the style guides with other animated style guidelines discussed in previous studies, evaluating how the traditional animation guidelines are contextualized and incorporated in the contemporary practices. After analysis, the study compares types of animation discussed in another study with the use of animations in the Tumblr app. Besides, the study presents some interesting considerations regarding the interface design process, such as types of animations and its benefits. 


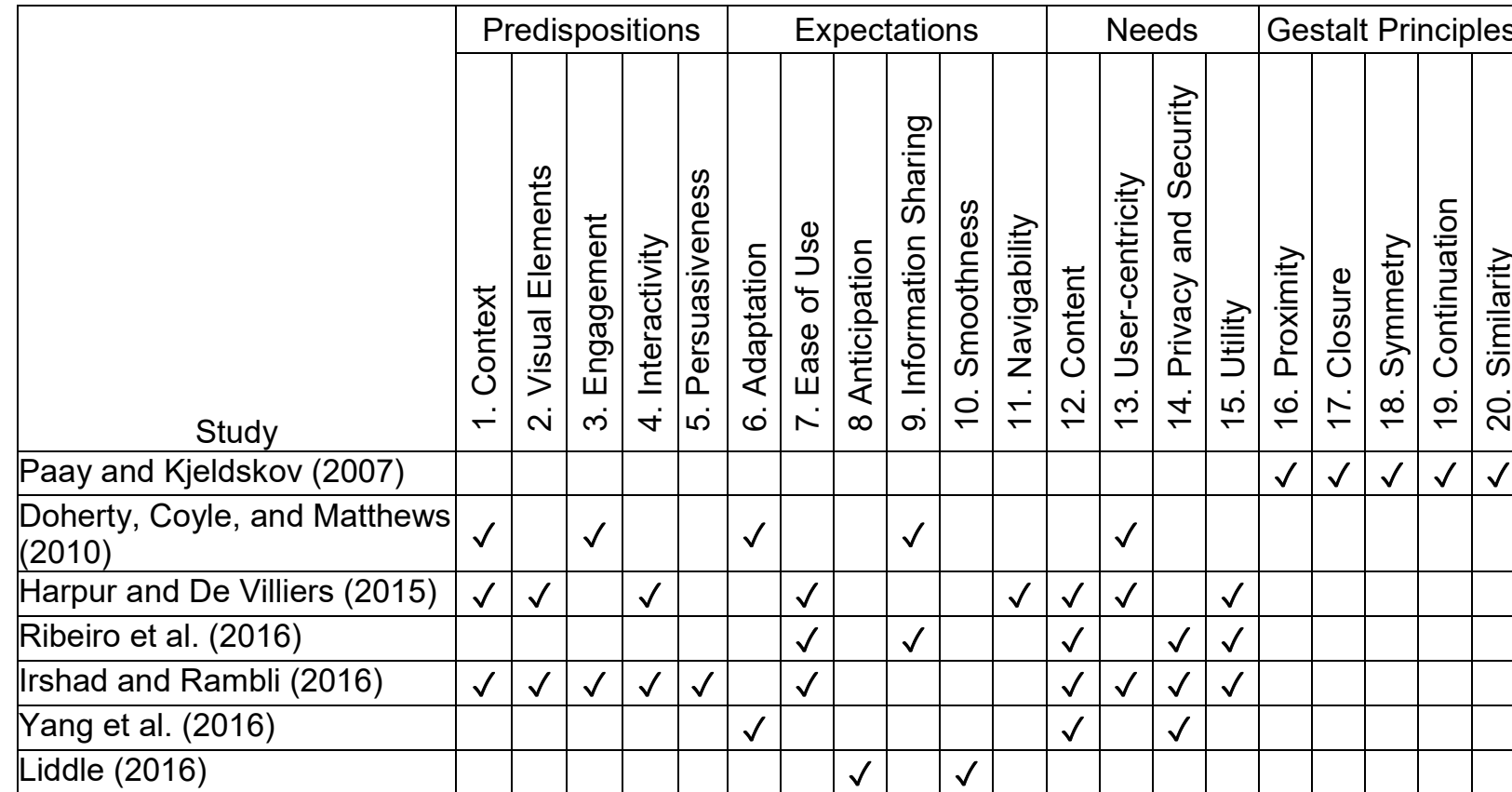

1. Context: Consider aspects related to the target audience, type, function, and app.

2. Visual Elements: Parts that compose the interface. Design a simple and attractive layout with appropriate colors.

3. Engagement: User's involvement with the interface along with interests, strengths, and ideas.

4. Interactivity: User's communication with the system. Design natural and high-fidelity interfaces.

5. Persuasiveness: Encouragement and promotion of specific user behaviors.

6. Adaptation: Use individual preferences to enhance the experience, where elements can adapt to user preferences.

7. Ease of Use: The interface must be easy to use for any user. Focus on simplicity, only essential information.

8. Anticipation: Result of a user's action must be obvious at all times, reducing cognitive load.

9. Information Sharing: Information exchange between users on the same network. For out-of-context apps, must be optional and user controlled.

10. Smoothness: Delicate interfaces with moderate elements. Elements must change continuously, avoiding major unexpected changes.

11. Navigability: Design an easy and intuitive interface. Establish an easy-to-follow, logically organized navigation flow.

12. Content: Data present in the interface. Offer content in an accessible and compact way.

13. User-centricity: User needs, wishes, and limitations. Involve users in the interface design process, incorporating their perspective.

14. Privacy and Security: Protect user's data, respecting their privacy.

15. Utility: Quality of something useful. Ensures that functions work correctly.

16. Proximity: Elements near each other are perceived as belonging together.

17. Closure: Things are perceived as a whole, even when part of the information is missing.

18. Symmetry: When things have symmetrical parts, they are perceived as a coherent whole.

19. Continuation: Elements are identified as continuous patterns.

20. Similarity: Equivalent things are perceived as belonging together.

Table 1. Guidelines used in the studies included in the systematic review. 


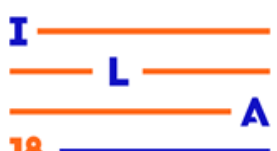

Liddle (2016) argues that a distinctive feature of the mobile interfaces is the limited screen space relative to a traditional workspace. Due to this fact, the arrangement and distribution of elements in the interface can change according to each device. Each mobile platform also encourages strong connections between individual application design and internal platform designs. Applications considered native to a specific platform can incorporate specific navigation patterns, iconography, and color palettes (all strategies conquered through the use of guidelines) to ensure consistency, clarity, and fluidity in the alternate use of different applications.

The study by Paay and Kjeldskov (2007) addresses the issue of how location-based mobile services placed in a specific context are perceived and understood by users. Data analysis is performed from the perspective of the Gestalt Theory, based on the discovery that people are efficient in absorbing and formulating a meaning from a small and fragmented piece of information when interacting with this type of application. According to the authors, the theory is also used in other humancomputer interaction studies applied in the design of interfaces to provide a theoretical understanding of how users probably perceive them. This theory consists only of a small subset of the original Gestalt laws, in the form of a smaller set of guidelines. The analysis performed in the study seeks to describe and explain the interaction between users, mobile devices and the context of use through the principles of the theory: Proximity, Closure, Symmetry, Continuity, and Similarity. These principles can be applied to UX and incorporated into different design guidelines, as reported by the authors.

Von Saucken, Michailidou, and Lindemann (2013) explain that approaches from several disciplines deal with UX. One of these approaches classifies UX into two categories: Macro UX and Micro UX. Macro UX targets the fulfillment of customer's needs and motives, regarding the experience holistically. It helps to set user-related goals for the right product's purpose on a conceptual level (HASSENZAHL, 2010). Micro UX focuses the product embodiment design without questioning its purpose. It addresses a pleasant embodiment design in detail concerning material, usability, and interface, specifically, without using abstract psychological terms (VON SAUCKEN; MICHAILIDOU; LINDEMANN, 2013).
From Table 1, guidelines 1, 3-8, and 13 can fit into the Macro UX approach. According to Saucken, Michailidou, and Lindemann (2013), Macro UX takes advantage of regarding the experience holistically, because leaving the product perspective and starting with the user and his needs gives the opportunity for a radical redesign of experiences and avoids the thread of sticking to existing product concepts. On the other hand, the approach of Macro UX requires changing the development process radically and therefore appears difficult to be implemented. The quality and location of information on a particular UI are also significant and directly affects the persuasiveness of users.

Still, from Table 1, guidelines 2, 9-12, and 14-20 may fit the Micro UX approach. Following these guidelines can bring some benefits. Saucken, Michailidou, and Lindemann (2013) cite the shortterm support without influencing existing development processes too radically with a satisfactory outcome. However, the benefit of Micro UX is limited as this only causes incremental improvements in details and does not question the product's purpose.

Von Saucken, Michailidou, and Lindemann (2013) also claim that UX needs to be implemented in real development projects by real designers and engineers, mostly without psychologists or ergonomists. The authors emphasize the need for rather short-lasting but effective tools and methods (from Micro UX) for developers, which they can understand and apply smoothly. In this context, most of the guidelines from Table 1 fits as effective methods to facilitate the work of designers and developers.

\subsection{Research Question 2: How is the user experience evaluated in the app for the formulation of a guideline?}

Table 2 expresses the evaluation methods and techniques applied in each study. The studies have both qualitative and quantitative research, often using both types of research in their work.

According to Kelle (2006), the use of a combination of qualitative and quantitative data can improve an assessment by ensuring that the limitations of one type of data can be balanced by the strengths of another, providing mutual validation of the domain under investigation. 


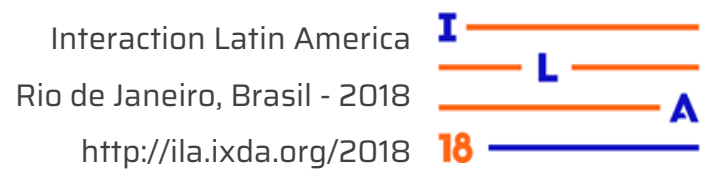

Applying a mix of both qualitative and quantitative methods is necessary to identify user needs; evaluate the interface against those needs and generate improvements. The right method will usually depend on the goals and stages of each research. Either way, results from qualitative and quantitative research lend support and depth to each other, serving different but complementary purposes (SAURO, 2016).

In this review, the number of individuals present at each evaluation and the target audience to which the test was directed varied according to the scope of the study.

The study of Irshad and Rambli (2016) involved 15 participants; all of them had a smartphone, except one. However, only one participant had previously used MAR technology. The studies of Harpur and Villiers (2015) and Ribeiro et al. (2016) had more than one evaluation phase, with different groups of users in each of them. In the first one, the research was conducted over two and a half years and involved four subsequent evaluations, each by two different methods, between two types of participants: expert evaluators and students. These evaluations led to the elaboration of four different versions of the mobile learning environment, incremented from the results obtained in each evaluation phase, with the purpose of developing a future final version using the set of guidelines formulated from the results. The second study cited was performed in two phases. The first one had 16 young adult participants divided into three focus groups, where they reported previous experiences with health-related applications, views on currently available applications in the area, desired resources in a health promotion application, and also factors that influence the long-term use of applications in this category. In the second phase, the group analysis led to the elaboration of an online questionnaire for a larger group of users. The results of the two phases were mapped, analyzed, and discussed, resulting in a set of guidelines.

Since they are studies of different nature, Paay and Kjeldskov (2007), Doherty, Coyle, and Matthews (2010), Yang et al. (2016), and Liddle (2016) do not specify the sample size of individuals. In these studies, the use of a population is not necessary, since other methodologies of analysis can be applied, considering the techniques listed in Table 2.

\begin{tabular}{|c|c|c|c|c|c|c|c|}
\hline Study & 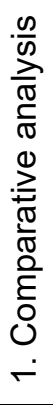 & 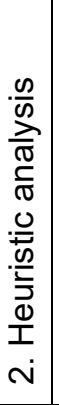 & 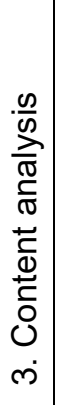 & 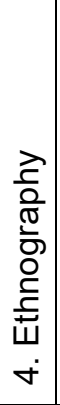 & 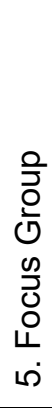 & 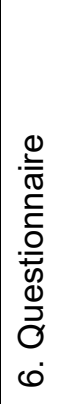 & 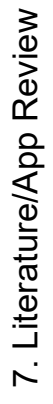 \\
\hline $\begin{array}{l}\text { Paay and } \\
\text { Kjeldskov } \\
(2007)\end{array}$ & & & $\checkmark$ & $\checkmark$ & & & \\
\hline $\begin{array}{l}\text { Doherty, } \\
\text { Coyle, and } \\
\text { Matthews } \\
\text { (2010) }\end{array}$ & & & & & & & $\checkmark$ \\
\hline $\begin{array}{l}\text { Harpur and } \\
\text { De Villiers } \\
\text { (2015) }\end{array}$ & & $\checkmark$ & & & & $\checkmark$ & $\checkmark$ \\
\hline $\begin{array}{l}\text { Ribeiro et al. } \\
(2016)\end{array}$ & & & $\checkmark$ & & $\checkmark$ & $\checkmark$ & \\
\hline $\begin{array}{l}\text { Irshad and } \\
\text { Rambili } \\
\text { (2016) }\end{array}$ & & & & & & $\checkmark$ & \\
\hline $\begin{array}{l}\text { Yang et al. } \\
(2016)\end{array}$ & & & & & & & $\checkmark$ \\
\hline Liddle (2016) & $\checkmark$ & & & & & & \\
\hline
\end{tabular}

1. Comparative analysis: Guidelines analysis for verifying certain design principles.

2. Heuristic analysis: Experts inspect interface in order to identify problems and strengths.

3. Content analysis (thematic): Analysis of patterns in a data set to group them by subject affinity.

4. Ethnography: Researcher observation to understand and describe social phenomena of a group.

5. Focus Group: Meetings with different user profiles to list their needs and expectations.

6. Questionnaire: Collection of information through written questions.

7. Literature or App Review: Review of guidelines in existing application interfaces and/or through a literature search.

8. Thinking-aloud: Verbalization of thoughts during interface interaction and navigation.

Table 2. Types of evaluations and assessments. 


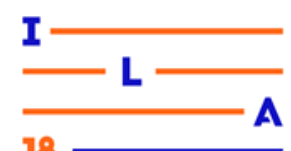

As stated by the authors in Yang et al. (2016), their attempt to enhance the mobile app with an adaptive interface encountered two problems. First, they did not have the information needed to infer what users most likely wanted to do. Second, they did not properly motivate users to provide useful information that would support the adaptation. The interesting conclusion pointed out by the authors highlight the importance of planning for adaptive interfaces in UX practice, tailoring the interactions to collect the required information. In their results, the authors promoted the lack of planning and provided design patterns that showed where and how adaptations could be added. Then, the authors elaborated an exemplar wireframed interaction flow to illustrate how design teams can capture and communicate their plans for adaptive mobile interfaces.

\section{Limitations}

There are some limitations to this study. We used specific research terms, which may not have captured all articles on the research topic. UX is a broad concept, which involves many factors, such as usability, environmental factors, previous experiences, and user's ability with the technology involved, emotions and hedonic variables among others. Hence, all these variables would be difficult to incorporate into a search strategy, which would probably return a high number of results, making it problematic to summarize the studies and synthesize the results.

\section{Conclusion}

This review identified seven studies from the literature that address the use of guidelines related to user experience in the interface design process and the mobile app development. Among the main reasons for the low number of studies identified on the subject matter are the absence of a detailed specification of guidelines, lack of clarity about the application being an interface, and insufficient information about the UX approach.

The results show the set of guidelines in this scenario is quite extensive, including many design principles in almost all categories, where there is great heterogeneity of information.

Since UX is subjectively and intimately tied to the intrinsic characteristics of each individual (e.g., desires, needs, limitations, etc.), applications should consider comprehensive and adaptable sets of guidelines, always focusing on the user profile and context.

Furthermore, results based on user-centered participatory studies can expand and enrich a set of existing guidelines and also help to create new ones. Guidelines can bring a number of design benefits to a more consistent and user-friendly interface, helping to reduce user confusion and frustration. Due to the fast and constant evolution of mobile technology, the task of formulating guidelines is always in development, along with the evolution of device resources and users' needs and desires.

More research on this topic must be performed in order to expand the knowledge of guidelines that incorporate UX, allowing the full understanding of issues, conditions, and peculiarities of each guide. Moreover, it is essential to evaluate the effectiveness of a specific set of guidelines on how much they influence the principles that condition UX at the various levels of design, along with user satisfaction, predispositions, expectations, and usage environment.

\section{References}

AHN, S.; KIM, Y.; LEE, T. UX design guideline of font-sentence properties by screen sizes to secure the legibility of people with low vision. In: Proceedings of HCI Korea. 2016. p. 514-521.

ANDERSON, P. Mobile and PDA Technologies: Looking around the corner. JISC Technology and Standards Watch, 2005.

App Annie. App Annie Market Forecast 20162021. 2017. Available at: $<$ https://www. statista.com/statistics/271644/worldwide-free-andpaid-mobile-app-store-downloads/>.

DOHERTY, G.; COYLE, D.; MATTHEWS, M. Design and evaluation guidelines for mental health technologies. Interacting with Computers, v. 22, n. 4, p. 243-252, Jul 2010.

FEDELE, G. et al. Can User Experience affect buying intention? A case study on the evaluation of exercise equipment. In: Proc. of the Human

Factors and Ergonomics Society Europe Chapter Annual Conference. Prague: HFES, 2016. V. 4959, p. $145-152$. 


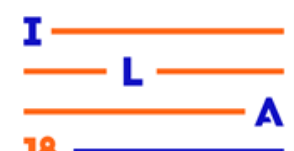

GALITZ, W. O. The Essential Guide to User

Interface Design: An Introduction to GUI Design Principles and Techniques, 3rd Edition.

Indianapolis: Wiley Pub, 2007. 888 p.

\section{GRILO, A. Psicologia Comportamental e Design}

de Interação. 2015. Available at: <https:

//brasil.uxdesign.cc/psicologia-comportamental-edesign-de-interacao-1de3f46b25e8>.

GSMA Intelligence. Infographic: Number of unique mobile subscribers worldwide hits five billion. 2017. Available at:

$<$ https://www.gsmaintelligence.com/research/2017/0 6/number-of-unique-mobile-subscribers-worldwidehits-five-billion/624/>.

HARPUR, P.; VILLIERS, M. R. (Ruth) de. Design guidelines for technology-enhanced learning via mobile devices in a tertiary education context in South Africa. In: Computer Supported Education. Cham: Springer, 2015. p. 141-159.

HASSENZAHL, M. Experience design: Technology for all the right reasons. Synthesis lectures on human-centered informatics, v. 3, n. 1, p. 1-95, 2010.

HASSENZAHL, M.; TRACTINSKY, N. User experience - a research agenda. Behaviour \& Information Technology, v. 25, n. 2, p. 91-97, Mar 2006.

IRSHAD, S.; RAMBLI, D. R. A. Design

Implications for Quality User eXperience in Mobile Augmented Reality Applications. In: Lecture Notes in Electrical Engineering. Cham: Springer, Cham, 2016. V. 362, p. 1283-1294.

KELLE, U. Combining qualitative and quantitative methods in research practice: purposes and advantages. Qualitative Research in Psychology, v. 3, n. 4, p. 293-311, 2006.

KITCHENHAM, B.; CHARTERS, S. Guidelines for performing systematic literature reviews in software engineering. In: Technical report, Ver. 2.3 EBSE Technical Report. EBSE. Keele: 2007. p. 57.

KUJALA, S.; VÄÄNÄNEN-VAINIO-MATTILA, $\mathrm{K}$. Value of information systems and products: Understanding the users' perspective and values. Journal of Information Technology Theory and Application (JITTA), v. 9, n. 4, p. 4, 2009.
LIDDLE, D. Emerging Guidelines for Communicating with Animation in Mobile User Interfaces. In: 34th ACM International Conference on the Design of Communication. New York: ACM Press, 2016. p. 1-9.

LOWDERMILK, T. User-centered design: a developer's guide to building user-friendly applications. O'Reilly Media, Inc., 2013.

MINHAS, S. Why You Need UI Guidelines? 2018. Available at: $<$ https://uxplanet.org/why-you-needui-guidelines-d380e407b759>.

NIELSEN, J.; BUDIU, R. Mobile usability. MITPVerlags GmbH \& Co. KG, 2013.

\section{NIELSEN, J.; NORMAN, D. The Definition of} User Experience (UX). 2017. Available at:

$<$ https://www.nngroup.com/articles/definition-userexperience/>.

PAAY, J.; KJELDSKOV, J. A Gestalt theoretic perspective on the user experience of location-based services. In: Conference of the Computer-human Interaction Special Interest Group (CHISIG) of Australia on Computer-human Interaction: Design: activities, artifacts, and environments. 2007, p. 283.

PANG, P. C.-I. et al. What are health website visitors doing: Insights from visualisations towards exploratory search. In: Proceedings of the 28th Australian Conference on Computer-Human Interaction. 2016. p. 631-633.

RASMUSSON, J. et al. Multimedia in mobile phones - The ongoing revolution. Ericsson Review, v. 2 , p. 10, 2004.

RIBEIRO, N.; ALMEIDA, A. M.; SANTOSSILVA, F. happy | Prevenção na palma da tua mão. 2017. Available at: <http://happy-app.eu/>.

RIBEIRO, N. et al. Guidelines for a cancer prevention smartphone application: A mixedmethods study. International Journal of Medical Informatics, v. 94, p. 134-142, 2016. 


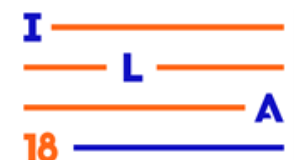

RIVERO, L.; CONTE, T. A systematic mapping study on research contributions on UX evaluation technologies. In: Proceedings of the XVI Brazilian Symposium on Human Factors in Computing Systems. 2017. p. 5:1-5:10.

ROGERS, Y.; SHARP, H.; PREECE, J. Interaction design: beyond human-computer interaction. 3. ed. Chichester, U.K: John Wiley \& Sons, 2013.

SANTOS, C. M. da C.; PIMENTA, C. A. de M.; NOBRE, M. R. C. The PICO strategy for the research question construction and evidence search. Revista Latino-Americana de Enfermagem, FapUNIFESP (SciELO), v. 15, n. 3, p. 508-511, 2007.

SAURO, J. The challenges and opportunities of measuring the user experience. Journal of Usability Studies, v. 12, n. 1, p. 1-7, 2016.

SAURO, J.; LEWIS, J. R. Quantifying the User Experience: Practical Statistics for User Research. Elsevier/Morgan Kaufmann, 2012.

TRIBERTI, S.; GAGGIOLI, A.; RIVA, G. Using and intending: How personal intentions can influence the user experience of interactive technologies. Annual Review of Cyber Therapy and Telemedicine, v. 14, n. November, p. 130-135, 2016.

VERMEEREN, A. P. O. S. et al. User experience Evaluation Methods. In: 6th Nordic Conference on Human-Computer Interaction Extending Boundaries. New York: ACM Press, 2010. p. 521.

VON SAUCKEN, C; MICHAILIDOU, I; LINDEMANN, U. How to Design Experiences: Macro UX versus Micro UX Approach. Design, User Experience, And Usability. Web, Mobile, And Product Design, p.130-139, 2013. Springer Berlin Heidelberg.

WEEVERS, I. App Design Guidelines For HighPerformance Mobile User Experiences. 2011. Available at:

$<$ https://www.smashingmagazine.com/2011/07/seve n-guidelines-for-designing-high-performancemobile-user-experiences/ $>$.
YANG, Q. et al. Planning Adaptive Mobile Experiences When Wireframing. In: ACM Conference on Designing Interactive Systems. New York: ACM Press, 2016. p. 565-576.

ZHANG, H.; ALI BABAR, M. Systematic reviews in software engineering: An empirical investigation. Information and Software Technology, Elsevier B.V., v. 55, n. 7, p. 1341-1354, 2013.

\section{Acknowledgments}

The authors would like to thank the Brazilian research funding agencies National Council of Scientific and Technologic Development (CNPq) and Fundação Universidade de Passo Fundo (FUPF). Acknowledgments to Nathália Cechetti for her technical assistance. 